\title{
DEVELOPING ADMINISTRATIVE SKILLS
}

Fred A. Crawford, Jr, MD

$T^{\text {hititan }}$ he fact that the word developing is included in the title obviously implies that academic surgeons do not have adequate administrative skills and that these skills must be developed. I am sure that, somewhere in the human genome, there is a sequence of amino acids that codes for administrative skills and that, in fact, a few of us are born administrators; but I will make the assumption that this is indeed rare and that these skills must be developed. So this article will be aimed at the large majority of us without such inborn skills.

I have been somewhat concerned about this topic for several reasons. The first is that, in my institution (and I suspect in yours), the administrators are not necessarily those individuals held in the highest regard by those of us on the front lines. So let me quickly distance myself from administrators. First and foremost, I am a clinical cardiac surgeon. Nevertheless, for 20 years I have served in administrative roles including Division Chief, Department Chair, and President of our physician practice organization. So I am familiar with the administrative aspects of academic surgery.

Second, it is somewhat difficult to separate administrative skills from leadership skills, because there is some overlap. It is my experience that leaders inspire, although administrators rarely do.

Third, my usual approach to a discussion like this is to research the topic thoroughly and then tell what others have said about it. This time I have decided to take a chance and simply tell you what I have found to be important and useful about this subject during my career. Obviously, there is considerable wisdom that others have contributed, and I encourage you to read what they have said about this topic.

Fourth, my biggest concern is that you might find this topic hopelessly boring, but let me try to convince you that it is extremely important.

From the Department of Surgery, Medical University of South Carolina, Charleston, SC.

Address for reprints: Fred A. Crawford, Jr, MD, Horace C. Smithy Professor Surgery, Chairman, Department of Surgery, Medical University of South Carolina, 96 Jonathan Lucas Street Suite 409, PO Box 250612, Charleston, SC 29425.

J Thorac Cardiovasc Surg 2000;119:S33-7.

Copyright $\odot 2000$ by The American Association for Thoracic Surgery. $0022-5223 / 2000 \$ 12.00+0 \quad \mathbf{1 2 / 0 / 1 0 4 7 2 4}$

doi:10.1067/mtc.2000.104724
Surgeons are frequently called on to serve as administrators, probably because of our decision-making skills. I was first exposed to this at Duke University. The importance of the role of surgeons as administrators was discussed by Hatcher in $1987 .{ }^{1} \mathrm{He}$ described the evolution of health care administration in the following statement

Prior to World War II, hospitals were run by doctors. As doctors entered military service, necessity demanded lay administrators, and by the end of the war, a new profession-hospital or health administration-had become established. This transfer of authority from physician to administrators continued largely by default, as physicians were pleased to be free from the administrative and business details of hospital management. ${ }^{1}$

He went on to say,

There are many capable and very cooperative hospital administrators, but there is no substitute for physician authority over the operation of a hospital. Physicians must be willing to accept administrative responsibility in their institutions. We prefer the operating room, and we love to perform surgery; but, as we mature, all of us must give some time to administration, and some of us must give all of our time. As much as we would like to do so, we simply cannot abdicate control of our work environment to others. ${ }^{1}$

This was an extraordinarily prescient observation and explains, in part, the current situation in many of the hospitals.

One of the most successful surgeon administrators that I know is Floyd Loop, MD, who, on top of an extraordinarily successful career as a cardiothoracic surgeon, now serves as CEO of the Cleveland Clinic. In his presidential address last year to the American Association for Thoracic Surgery, he stated, "The single greatest lesson I have learned in management is that medical centers should be led by physicians. It is easier for a physician to learn business management than for a business man to learn medicine." 2

These comments by these 2 outstanding academic cardiothoracic surgeons clearly illustrate the need for young academic surgeons to acquire administrative skills.

I believe that academic surgeons must be clinical surgeons first, and investigators second, but I also agree with Drs Hatcher and Loop that involvement in administrative activities is essential. Most young aca- 
demic surgeons who have just completed a difficult surgical residency are most interested in first proving that they can operate independently with good outcomes (certainly that was my initial goal). The second priority for most is to develop a credible investigative/research effort. The expectation is that the Division Chief or Department Chair will take care of all the necessary logistical arrangements, such as adequate operating rooms and sufficient research space, to enable us to reach these goals. Most beginning academicians are not remotely interested in the administrative effort required to make these things happen. In fact, it is possible to have a reasonably successful "academic" career, particularly on a primarily clinical tract without acquiring many administrative skills or without being involved administratively. But if you are going to be more than a uni-dimensional faculty member, one who aspires to other goals such as a Division Chief or Department Chair or especially to national leadership roles, then involvement in administrative activities and the development of administrative skills are important tools to enable you to reach these goals and more importantly to help you do a good job when you get there. Even if your aspirations are not so lofty, administrative skills allow you to have a significant impact on the day-to-day running of your hospital instead of simply complaining about how poorly others are doing it.

What is it that we administer as academic surgeons? Fundamentally, we administer people, programs, and budgets. At the departmental level, the people part includes faculty members, residents, medical students, and staff. Programmatic areas include residency programs, research programs, outreach programs, postgraduate education programs, compliance programs, and quality improvement programs to mention a few. Budget administration is arguably the most important of all, because unless you find a way to get the dollars and then spend them wisely, none of the programs, no matter how well conceived, will be successful.

At the institutional level, surgeons are traditionally viewed as "take charge" people who can be counted on to get a job done, and we are frequently asked to help manage important units (such as trauma, burn, and intensive care units). Larger institutional administrative commitments might include directors of centers such as heart centers or cancer centers. At the highest institutional levels, academic surgeons are called on to serve as directors of faculty practice plans, as Dean, Provost, and even as President of the institution. There is a great tendency to think when you begin an academic career that you would never be interested in such positions, but, if you truly want to influence the direction of your institution, involvement in administration is essential.

At the national level, we have all admired those surgeons who have served as leaders of significant organizations such as Residency Review Committees and boards such as the American Board of Surgery and the American Board of Thoracic Surgery, as well as those who have served in important roles in our national organizations such as the American Association for Thoracic Surgery and the Society of Thoracic Surgeons. Significant administrative skills are necessary in each of these academic surgical roles. I hope that this convinces you that administrative skills are important and even useful. Now, what are those skills and how do we acquire them?

Perhaps the most important skill is time management. If you do not take control of your schedule, others will take you prisoner with no possibility of parole. Although not all of the available time belongs to you, it is important that you control it. Some time belongs to your immediate superior. When the Dean calls and asks me to chair an important committee, this is not only an imposition on my available time but also an incredible opportunity to influence the direction of the institution and a department with which I and my faculty interact on a daily basis. It is important to choose these assignments wisely (you really do not have time to do them all) but look for opportunities that will be useful to you or your department as a trade-off for the time that you give up.

As a Department Chair or Division Chief, some of your time belongs to your faculty. Faculty recruitment is a continuous process and takes up an incredible amount of time. Yet it is part of the job and also an opportunity to meet some extremely interesting people. Time devoted to faculty also includes mentoring, periodic evaluations, department and division meetings, dispute mediation, and time devoted to logistical problems, such as laboratory space.

A significant portion of an academic surgeon's time belongs to patients and clinical responsibilities. You must decide, working with your Division Chief or Department Chair, how much of your time you are going to commit to this activity. That portion that is committed must be totally committed. You cannot leave a sick patient on the operating table just because you are late for a meeting with the Dean. As a Department Chair, it is relatively easy to almost completely avoid patient contact altogether. However, I sincerely believe that you will lose the respect of your faculty, residents, and colleagues if you only pay lip service to your clinical responsibilities. Remember, you can do something 
that no full-time administrator can do; you can repair a heart or remove a lung and restore a patient's health. This is an incredibly important power base from which to perform your administrative activities.

Some of your time belongs to your residents and medical students. Teaching is a part of the responsibilities of an academic surgeon. You must set aside time for teaching and not let this be interfered with. I was always impressed that Dr. David Sabiston invariably kept his commitment to his teaching sessions with his students and residents no matter how busy his schedule. As a Department Chair, I have been disappointed to find that time to teach at the student level has been increasingly difficult to set aside and is something that I am committed to correcting.

Some of your time must be directed toward administrative duties, such as institutional meetings. Unfortunately very little substantive happens at many of these meetings, but if you are not there, your pockets may get picked. If you are going to take the time to attend, do your part to be sure that the meeting is well organized, follows an agenda, and starts and finishes on time. We all know administrators who go to 6 or 8 meetings a day and leave at the end of the day thinking that they have accomplished something significant. As surgeons, we are far too busy for this. It is important to pick the meetings at which you can make the most impact.

Eventually you may be asked to assume administrative responsibilities outside your parent institution. Do not let this go to your head. Always remember that your success at home is what enabled you to reach this level and accordingly be sure that you remember to take care of your responsibilities in your parent institution first before taking care of these other responsibilities.

Time must be reserved for your family. It is easy to overlook this commitment, especially when you are starting your academic career. Don't. Your family needs you, and you need them. Do not come home from the laboratory 1 day to find your children in college.

Finally, reserve some time for yourself. Use some of this time to take care of your health, both physical and mental. I think it is essential to develop meaningful outside activities that direct your attention away from the institution and profession for periods of time so that, when you return, your focus is sharper. All of this makes it sound as if you need a 50-hour day, and sometimes you do; but, if you control and effectively manage your time, all of these things can be accomplished.

One of the tools that is most useful in time management is prioritization. All crises are not life-threatening. All resident problems are not equal. All faculty disputes do not have to be resolved before sunset. But some do. Learn which ones require more time and which ones require less time; which ones need resolving today, and which ones can wait. In a now outmoded term, do not become a prisoner of your "in box." I guess the current phraseology would be "don't answer every e-mail the moment your computer beeps." Learn to prioritize. Part and parcel of time management and prioritization is organization. If you have your time under control and if you prioritize successfully, you will become well organized.

Another administrative skill that must be acquired is the ability to plan effectively. It is all too easy to drift from day to day, especially if things are going reasonably well, without spending much time or effort on planning for the future. After all, if today's case went okay and if you have another hard 1 tomorrow, that is sometimes as far ahead as you can think. But it is absolutely essential to plan for the future if you are going to have any control over what happens.

Planning can be tactical or strategic. Tactical planning focuses on the short-term and specific issues and is helpful in successfully getting through the week or month. Strategic planning usually involves more complex issues and projects further into the future. I have found the strategic planning process, especially when carried out with the help of skilled assistants or consultants, to be extraordinarily useful. At times the process itself can be as helpful as the actual plan that is generated. But the process is not the only thing, because a wonderful strategic plan, once developed, is of little use if simply consigned to the hard drive or filing cabinet and never implemented. Obviously, the ability to implement successfully is a very important administrative tool.

It is important to set aside time for both strategic and tactical planning. Some issues simply cannot be resolved in the monthly department meeting but need to have adequate time for careful consideration of all alternatives and a decision-making process that allows buy-in by all members of a particular group. Early on as a Division Chief and Department Chair, I felt that setting aside time for planning was wasteful, especially if we had to give up valuable operating time to do so. However, 1-day focused retreats, if they are held on an infrequent basis, can be extremely useful in determining the future direction of a division or a department.

Even if you plan, prioritize, and manage time well, you will quickly learn that you cannot administer everything yourself. Therefore you must learn to delegate. First in this process is learning what can be delegated and what cannot. In other words, learn what must be done by you and what can be successfully carried 
out by others. Second, to delegate you must have a team in whom you have complete trust. You must be confident that, if a task is delegated, it will get done correctly and in the manner in which you want it to be with little additional guidance from you. Do not try to economize on this team. Spend what it takes to get first class assistance. For a department chair, this team might include a trusted Administrative Assistant who arranges recruiting visits, visiting professorships, etc, without your assistance; a Business Manager who represents you at Deans meetings that you cannot (or do not want to) attend; and Division Chiefs and Section Heads who run an area in the department with minimal guidance from you. An essential administrative skill is the ability to develop a trusted team to whom you can delegate important jobs with the confidence that they will get done well.

Some fundamental knowledge of economics and accounting is extremely helpful to the academic surgeon. Perhaps the single most important or useful preparation for becoming a department chair occurred to me during my junior year in undergraduate school. I thought I had signed up for an economics course devoted to economic theory. Instead, it was a relatively straightforward accounting course that taught me 1 extremely important lesson-the left side of the ledger must balance the right side. In my institution (and I suspect in yours), no one is likely to step forward to take care of budget deficits that have occurred because of poor financial administration at any level in the Department of Surgery.

Administration is about decision making. Decision making is easy if you have good information. Surgeons have an advantage over other physicians and administrators in the area of decision making. We are trained to gather the relevant information as quickly as possible and then to make life or death decisions in the operating room on a regular basis. This makes administrative decision making relatively easy. First, there is generally more time available so that your information about a particular problem has the likelihood of being more complete than is true in the clinical arena. Second, relatively few administrative decisions are life or death anyway. Almost always these decisions can be revisited tomorrow or whenever.

Assuming that we can make decisions if we have the information, how do we go about getting it. First of all, it is important to know your sources. There will be no shortage of individuals interested in giving you their viewpoint on a particular problem or event. Almost invariably this information will be biased by that individual's agenda. Accept the information from that source but seek other opinions about the same problem. Have someone you trust to be completely unbiased and who is available to gather the information for you. In my case, it is my Business Manager who provides me with an incredible amount of relevant information from budget data to faculty work efforts to topics I have asked him to investigate. Perhaps most importantly, get out and find out for yourself. If you work in the office and never go to the operating room, you simply will not learn first hand of the daily problems encountered by your faculty, residents, and staff. By remaining clinically active and involved in investigative efforts, you will be able to keep your finger on the pulse of your clinicians and your investigators and better appreciate their problems. It really does help to get out and fly the flag around the hospital and the laboratories.

Once you have gathered data and made a decision about an issue, inform those most affected about the decision, and keep them informed. Not every administrative decision that you make will be popular or greeted with the display of enthusiasm that you think it warrants. But if the decision is fair and those involved are kept in the loop, it will generally be accepted. I have found that regular department and division meetings in which there are wide-ranging discussions about mutual problems are useful administrative tools. I have also found that an open-book policy regarding finances works best.

Finally an administrative skill that is frequently overlooked is the ability to pass these skills down to those in administrative positions below you. By helping those in line behind you to acquire administrative skills, you ensure the development of a group of individuals who can be of enormous help to you not only today but also more importantly who will ensure the administrative unit's ability to sustain itself successfully after you are gone.

Now that we have identified some administrative skills that are useful, how can they be acquired? Like anything else in medicine, it is first necessary to acquire an appropriate fund of knowledge. Administrative skills are not taught in medical school and rarely to any extent as a part of general or cardiothoracic surgical residency programs. Probably the first real need for such skills comes as Chief Resident in general surgery, especially if you are asked to serve as Administrative Chief Resident. At that point you first learn of the joys of trying to keep everybody happy while getting the work done. You learn that everybody cannot have Christmas off and how understanding your coworkers are about this and other similar issues.

Acquiring a fund of knowledge about administration can best be done initially in a very traditional way, by 
reading. Instead of "how to" books, I have found it more useful to read about individuals who have proved their skills as administrators such as Jack Welch, the CEO of General Electric, ${ }^{3}$ or Andrew Grove, the CEO of Intel. ${ }^{4}$ Insights gained by these individuals on their way to the top of huge organizations are quite helpful and can be applied to medicine as well.

However, just as it is impossible to become a good surgeon by simply reading about it, the same holds true for administration. Although a good fund of knowledge serves as the foundation, usually the next step in our surgical education is watching and assisting master surgeons as they operate. Hopefully in this process, one learns surgical skills that you want to adopt and a few that might best be forgotten. The same is true for administrative skills. If you carefully observe individuals in your division or department and around your institution, you will find people who do a great job as administrators at a variety of levels. You will also find some who, despite all logic, have risen to top academic levels and yet who are hopelessly inept as administrators. I encourage you to carefully observe the leaders in your institution and those you come into contact with at the state and national level and to adopt those things that appear to work and to discard those things that do not. Do not continually try to reinvent the wheel. It is likely that someone has already tried about everything you can think of. Find out who did it and why it succeeded or failed and then proceed.

After reading and observing, the next step in surgery is to actually perform or practice operations, hopefully with good supervision at first and then, if successful, independently. This is true for administration as well. This means that you should actively seek administrative opportunities early in your career, even at the risk that these might have some adverse impact on your clinical or investigative activities. Do not try to take on every "opportunity" that is offered, but do not run away from them either or hide in the operating room or the laboratory. Find someone you trust to help you and take on the job. You may learn quickly that this is an area that you do not enjoy at all and that you prefer to leave it to someone else. But do not simply default until you have tried it. You may also find that the administrative genetic code has been expressed in you and that it may open future career opportunities.

I hope that this overview has convinced you of the need for the academic surgeon to develop administrative skills. Those skills that I have listed are useful, but by no means is the list meant to be all inclusive. Develop a fund of knowledge by reading, observe successful surgeon-administrators, and look for a chance to use these new tools.

\section{REFERENCES}

1. Hatcher CR. There is life outside the operating room. Ann Thorac Surg 1988;45:117-21.

2. Loop FD. The first living and the last dying. J Thorac Cardiovasc Surg 1998;116:683-8.

3. Slater R. Jack Welch and the GE way. New York: McGraw Hill; 1999.

4. Grove AS. Only the paranoid survive: the threat and promise of strategic inflection points. New York: Currency Doubleday; 1996. 